\title{
Uncle Sam's Ground Schools for Flyers
}

\section{Giving Observers Practical Experience in "Spotting" on a Miniature Battlefield}

\author{
By C. H. Claudy
}

THE War Department says, "It must be remembered 1 that the flying officer is not an 'aerial chauffeur' or 'exhibition flyer.' He has been more correctly defined as a twentieth century cavalry officer mounted on Pegasus.'”

A cavalry officer, whether mounted on a Pegasus of cloth and gasoline engine, his regular mount, or an army mule, has got to know considerable about military science if he is going to be an asset and not a liability.

Hence it is that the "ground school" for candidates for aviation commissions are becoming more and more important in the eyes of military authorities. A brigadier-general in the British aviation corps has said: "The longer the war continues the more we realize the vital necessity of the work done in ground schools and the need for learning more and more subjects which previously were not taken up until the would-be flyer stepped into his machine."

With the urgent necessity to supply pilots and observers for the 22,000 airplanes the United States is now building or about to build (no information as to the actual state of this building program is being given out by the Aviation Service of the Signal Corps) the establishment of "ground schools" where young men who can pass the necessary physical and mental tests are instructed in the thousand-andone things they need to know before they ever set foot in a machine, became immediately essential.

The development was typically American. On the first of last May General Squiers, Chief Signal Officer, commandecred the services of Prof. (now Lieutenant Colonel) Hiram Bingham, who until then was teaching at Yale University. Intensely interested in aviation, Prof. Bingham had made many flights and studied the subject from all angles. He did this, believing aviation would play the deciding part in the war, and wanting to get into it, even though age debarred him from active'service. When the need came for an instructor who could instruct, Prof. Bingham was ready and waiting.

With a corps of assistants he made a rapid but thorough inspection of the military aeronautics schools of the Royal Flying Corps at Toronto, sat up nights planning, consulting and thinking, and within ten days started six American Ground Schools. Two more have since been added, and all are doing work about which the general public knows little, but which is vital in the aeronautic campaign for "putting out Germany's

The American schools are located at the following colleges: University of California, Cornell, Georgia School of Technology, Princeton University, University of Illinois, Massachusetts Institute of Technology, Ohio State University, and State University, and University of Texas. Although they have taken over a large part of the technical apparatus and some of the instructors of the universities on whose grounds they are situated, they are in no sense a part of the university or of the ordinary university course. They are Army posts administered and supplied by the Schools Section, Air Division United States Signal Corps.

It is well that it is so. No University student would submit to the knowledgecramming process which students at the ground schools must stand. Within eigh weeks these young men have to assimilate a variety and amount of informa tion which would be staggering if cataloged. There is no

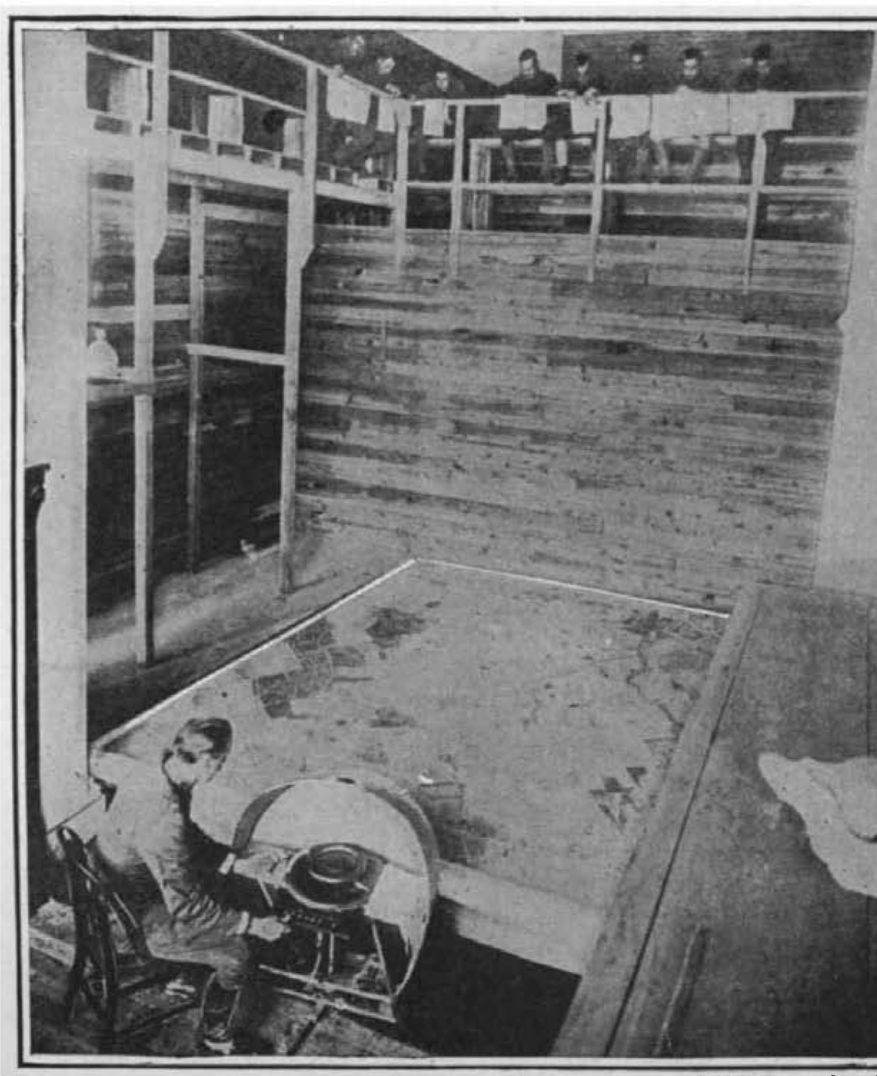

Testing the "spotting" ability of airplane observers by making flashes of light on a battlefield reproduced as it would appear from an elevation of 6,000 feet time wasted about it, either. Students begin their day at 50 A. M., and tumble into bed at 9.30--and those who chools and between

Reveille, first call 5.30, Assembly, 5.45, Calisthenics until 6.00, Mess, first call, 6.15, Assembly, 6.20, Inspection, first call, 7.20, Telegraphy, 7.30, School, first call, .55, Assembly, 8.00, School, first call, 8.55, Assembly, 9.00, School, first call, 9.55, Assembly, 10.00, School, first call, 10.55, Assembly, 11.00, Recall, 12.00, Mess, first call, 12.10, Assembly, 12.15, School, first call, .55, Assembly, 2.00, School, first call, 2.55, Assembly, 5.00 , ave seen these schools say that there is no need of having to to keep them awake until taps! The day's program-with minor differences between

No young man should shy away from the service because he fears his physical attainments are not up to standard. Trapeze performers, boxers, jiu-jitsu experts or other athletes who have quick nervous reaction and strength are welcome. But so are any young men with good bodies and good brains. The ground schools will do the teaching if the youth of the country will give them the material.

Having the men, the course proceeds on Colonel Bingham's theory that only a chap who can stand cramming can make a good aviator-and they proceed to cram him. The first three weeks of the course $c r$ "junior wing" takes up military study. Infantry drill in the school of the soldier, the school of the company, physical training, and first aid, are well inculcated. There are lectures on military courtesy, organization nd administration of the United States and modern Furop armies, European armies, Army paper work, military hygiene, etc. The junior wing machine gun and in wireless telegraphy, and in between are athletics, drills, more lectures and again drill, drill drill.

In the fourth week the "senior wing" subjects are taken up. Theory of flight, engines, telegraphic signalling, the use of aerial instruments, (barometer, compass, speed indicators, inclinometers, barograph, etc.), come first. Then classes in airplane rigging, repair of planes and engines, construction, types of airplanes are taken up in the fifth week in addition to the courses in telegraphic signalling, engine work, laboratory work, machine gunnery, etc., which go on all the time. Later come lectures on radio work, air fighting, map reading, meteorology, bombs and aerial photography.

The instruction, of course, is of the most practical kind. The education is intensive to the $n$th degree. What the ground

Retreat, first call, 6.05, Assembly, 6.10, Mess call, 6.15, School call, 7.30, Tattoo, 8.30, and Taps, 9.30.

Only a man of good physique and perfect health can stand a program like that. Only a man with brains can make use of it. Young men are desired-men from ineteen to thirty generally, "although in exceptional cases", to quote the official announcement, "older men of their lives out of doors, in the saddle, ranching, playing polo, mountain climbing, or in actual flying, may be accepted if they can satisfy the examining board of their physical fitness."

Physical fitness means perfect nerves, perfect eyes, perfect hearing, physical strength, perfect health. Light men are preferred to heavy ones, and slight builds have as good chance as stocky, providing the slightness does not mean thinness.

to the nth degree. What the ground aerology who can merely pass a brilliant theoretical examination.

An instance will show how practical the instruction is. In a ground school "scmewhere in America" a visitorsupposing a visitor could gain admission-would find several dozen young fellows intently studying a miniature battlefield. This "battlefield" might be called a map, were it not for its huge size, and the fact that flashesmitations of exploding shells, take place upon its surface at disconcerting intervals and unknown lccations. A tructure of scaffolding surrounds the "battlefield," and on top is another corps of young men, intently watching and locating these flashes as they occur.

The young men at the base of the structure are impersonating artillery officers. Those overhead are pilots and observers, supposed to be in an airplane. And to make the game real, there is real wireless, and the men above signal to those below in the cryptic code of the map squares, to "locate" the hits and correct the "range" of the "guns." "W- 28 E-6-8" buzzes the wireless. Another flash, a quick survey and "E-7-A 11 " comes the signal. At first the "pilots" are slow, wavering, undecided-later they become certain and quick, and the buzz of the wireless comes almost instantly after the flash.

No theory here. Men are being taught as well as they can be without actually being in a place high in the clouds above a real battlefield,what it is like to see the it is of a to (Concluded on page 7?) 

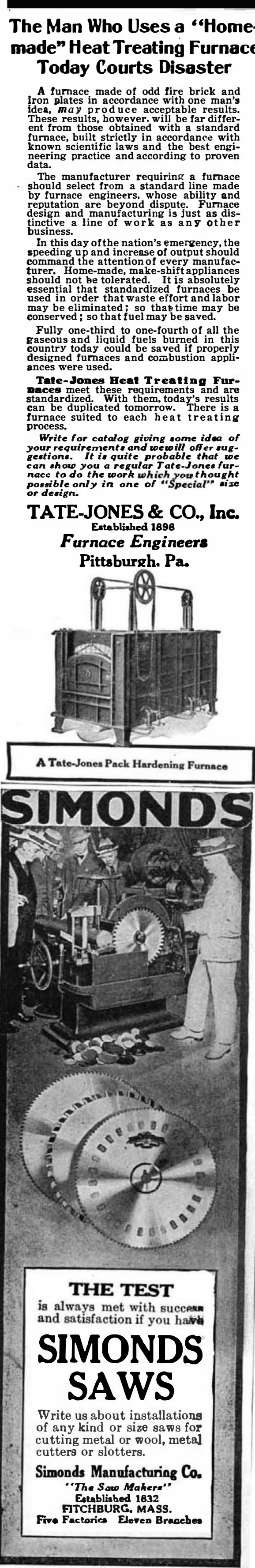

Uncle Sam's Ground School for Flyers light of an exploding shell, how it is located, and what sort of signals to send down to earth that they who are shooting, or being shot at, may know what to do with their guns of offense and defense.

The instruction in all the work is practical. Theory is included, but theory comes second. It is less important that a man know how a wireless functions than that he know how to work it. It is not so vital that the pilot understand the theory of gunnery, as that he know how to help his gunners. And it is practice, practice, practice which the ground school student has, all day long.

Some drop by the wayside. Not all who take the course are certified as having within them the makings of competent pilots or observers. Only those who are first class can qualify. For it is an expensive matter, this training of men, and their responsibility will be great-and there must be little waste.

The French war office figures that pilot and observer who, fully trained mounted, and equipped, cross the enemy trenches for the first time represent total investment of $\$ 25,000$.

The British figure that a fully trained pilot represents an investment of $\$ 6,000$, the observer $\$ 3,000$, and the two-seated ma chines $\$ 10,000$, which with other overhead expenses, bring the figures to the same total as the French. If for no other than financial reasons, the tremendous importance of the ground schools must be appreciated, not only in laying the prope foundations of this training but in weeding out the poor material and making the utmost of the good material.

After eight weeks of training and a stiff examination, the candidate learns his fate. Perhaps only 16 or 17 of the original class of 25 remain to graduate. But those who do have mastered the basic principles of military aeronautics, which, as Army men are learning more thoroughly every day, is a vital pre-requisite to any training in the air.

Successful ground-school graduates are enlisted in the Signal Corps or the Signal Enlisted Reserve Corps, where their status is that, of "flying cadets." As soon as they pass the test for reserve military aviatons they receive an officer's commission, with the regular pay and what is known as commutation of quarters at all places where no public quarters are available.

In the case of foreign duty, a ten per cent extra allowance is provided for by law to officens serving beyond the limits of the United States with the exception of the Canal Zone, Panama, Porto Rico, or Hawaii. In addition aviation officers o duty requiring them to participate regularly and frequently in aerial flights receive a 25 per cent increase in the pay of their arade.

It is a big job America has undertake - to create out of nothing a huge fleet of planes, and an army to fly and observe in them. It has been said abroad that we couldn't do it-in time. But it hasn't been said lately. Since the first foreign missions came over and observed America and America's methods there has been change of feeling as to what we could and couldn't do. And in place of bein skeptical, the Allies have sent us their best aviation experts to assist us in doing what at first they said we couldn't do.

Of course, we can do it, will do it-are doing it. And while the flyer in the air, dropping bombs or fighting a duel, is the spectacular end of the training, it is the ground school which lays the foundation and which, almost unknown to the general public, is doing a work of military importance second to none.in the final creation of America's aerial fighting corps. Dr. Hugh Robert Mills

D. Hugh Robert Mills, the veteran British geographer and meteorologist and director of "British Rainfall," has been awarded" the Symons gold medal of the Royal Meteorological Society. This medal is conferred every two years; alternately on a British and a foreign meteorologist.

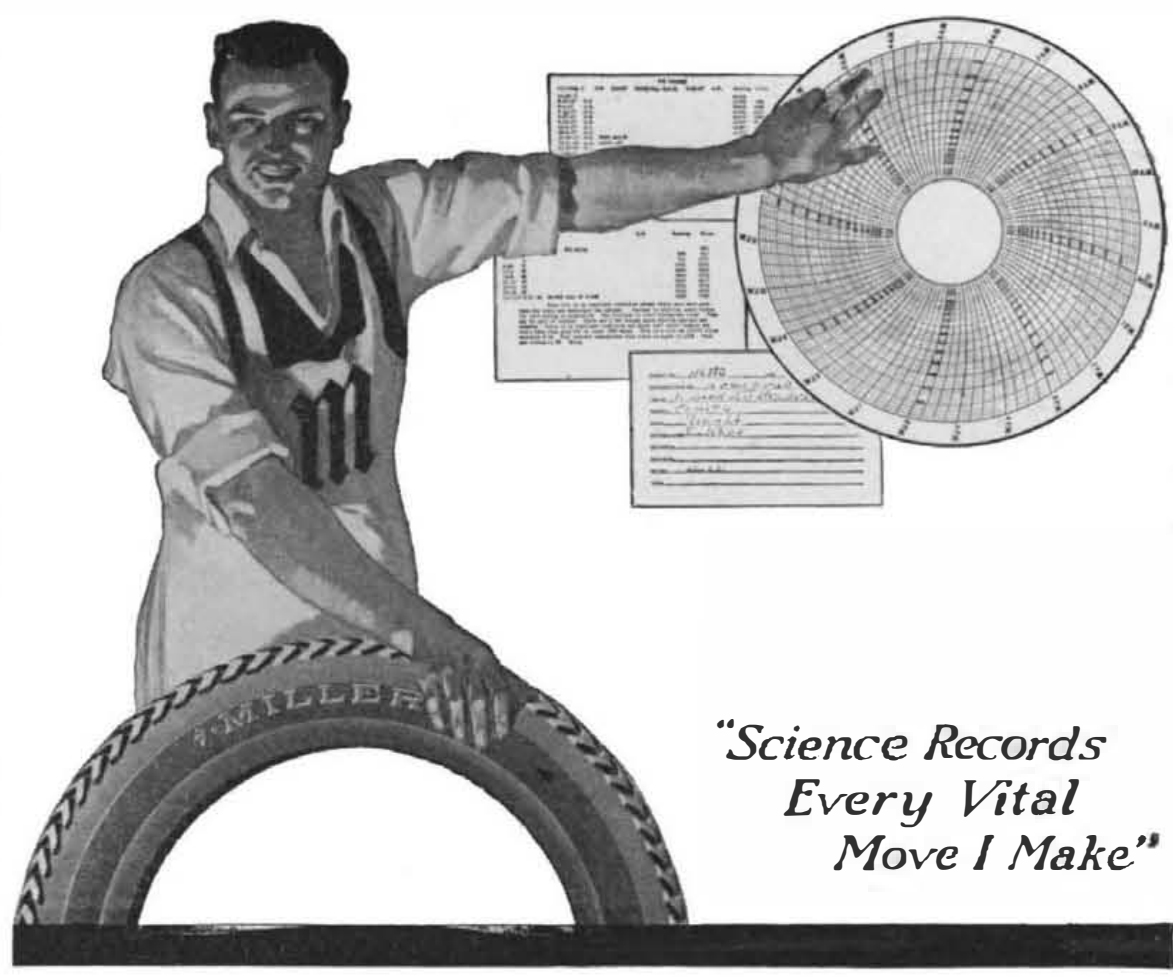

\section{Uniform Mileage} The Crowning Tire Triumph

\section{Due to Uniform Tires-Built by Champions}

A MIGHTY response has greeted the Miller announce-

ment that Uniform Tires are now an achieved fact.

That this world-gift is ready-that stabilized mileage is here after years of vain trials.

Previously, Miller Tires varied in mileage as others do.

Now 99 Millers in 100 outrun standard guarantees.

Run two Millers on opposite wheels and you shall see. Thousands of tests like this prove Miller mileage is stabilized.

\section{Miller@Tires

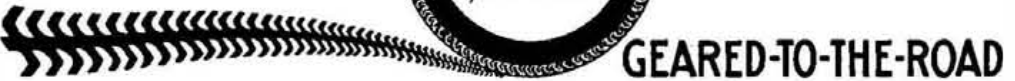

Mechanical methods do not account for this triumph. For they are shared by all makers.

But tires contain much handwork. And Miller has excelled by conquering "human variables."

To make workmanship uniform, we had to make workmen uniform. We had to take picked men only. Then we had to make each man a master tire builder.

\section{Tires 99\% Excellent}

Today these Miller experts are called champions.

Their personal efficiency averages 96 per cent. If a tire comes back their rating is penalized. But less than 1 per cent of the tires they build ever need adjustment. That means that Millers are 99 per cent excellent.

\section{Geared-to-the-Road}

In addition to stabilized mileage, Miller Tires give utmost safety. One reason is they are geared-to-the-road.

Their ratchet-like tread engages the ground as you go. This counters the tendency to skid.

\section{Few Can Get Them}

Such tires as these cannot be produced where quantity output rules. For picked men are rare. It takes years to make champions.

If you want to be sure of getting Millers this year you must reserve your supply at once. Only enough for one motorist in $\mathbf{5 0}$ will be made this year.

Miller Cord Tires are the fine, big fellows with the extra large air-capacity. There is nothing more luxurious, yet they cost less per mile than the regulation type.

THE MILLER RUBBER CO., Akron, Ohio Mators of Miller Red and Gray Inner Tubos,
Tho Tram-Mates of Uniform Tirs

Branches and Distributors In All Principal Cities

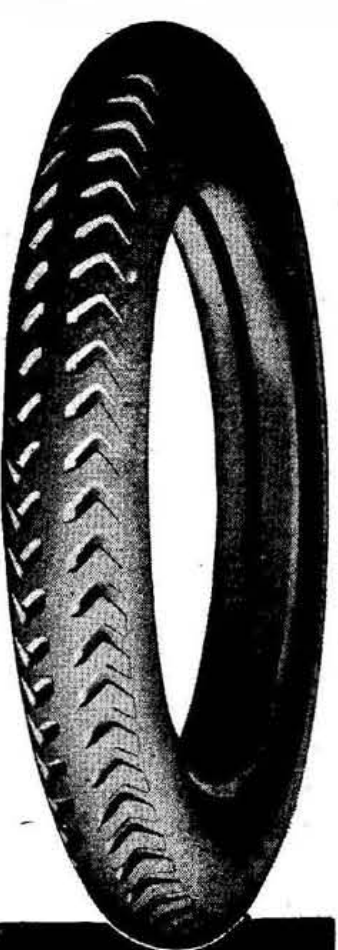

